\title{
PET CLINICS
}

\section{FORTHCOMING ISSUES}

April 2015

PET/CT and Patient Outcomes, Part I

Rathan M. Subramaniam, Editor

July 2015

PET/CT and Patient Outcomes, Part II

Rathan M. Subramaniam, Editor

October 2015

PET-Based Interventions

Rakesh Kumar, Editor

\section{RECENT ISSUES}

October 2014

Contribution of FDG to Modern Medicine, Part I

Søren Hess and Poul Flemming Høilund-Carlsen, Editors

July 2014

PET/CT Imaging in Tracers Beyond FDG

Mohsen Beheshti and Chun K. Kim, Editors

April 2014

FDG PET/CT Imaging: Normal Variations and Benign Findings

Mohsen Beheshti and Chun K. Kim, Editors

\section{RELATED INTEREST}

Radiologic Clinics, September 2014 (Vol. 52, Issue 5)

latrogenic Conditions of the Chest, Abdomen, and Pelvis

Gabriela Gayer and Douglas S. Katz, Editors

Available at: http://www.radiologic.theclinics.com

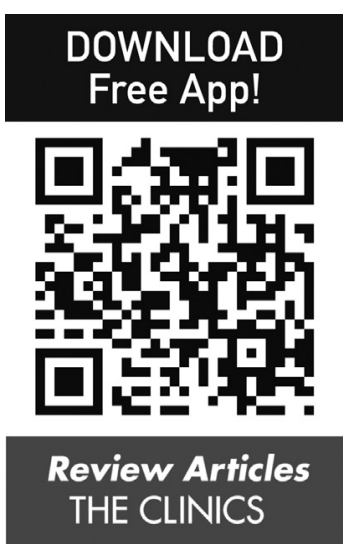

